\title{
Radial versus femoral access in patients treated with percutaneous coronary intervention and rotational atherectomy
}

\author{
Rafał Januszek $^{1,2}$, Zbigniew Siudak ${ }^{3}$, Krzysztof P. Malinowski ${ }^{4}$, Krzysztof Reczuch $^{5}$, Sławomir Dobrzycki ${ }^{6}$, \\ Maciej Lesiak7, Michał Hawranek ${ }^{8}$, Robert J. Gil ${ }^{9}$, Adam Witkowski10, Wojciech Wojakowski1" \\ Andrzej Lekston8, Mariusz Gąsior ${ }^{8}$, Wojciech Wańha11, Dariusz Dudek², Stanisław Bartuś13 \\ 1 Department of Cardiology and Cardiovascular Interventions, University Hospital, Kraków, Poland \\ 2 Department of Clinical Rehabilitation, University of Physical Education, Kraków, Poland \\ 3 Collegium Medicum, The Jan Kochanowski University, Kielce, Poland \\ 4 Institute of Public Health, Faculty of Health Sciences, Jagiellonian University Medical College, Kraków, Poland \\ 5 Department of Cardiology, 4th Military Hospital, Wrocław, Poland \\ 6 Department of Invasive Cardiology, State Teaching Hospital, Medical University of Bialystok, Białystok, Poland \\ 7 1st Department of Cardiology, Poznan University of Medical Sciences, Poznań, Poland \\ 8 3rd Department of Cardiology, Silesian Centre for Heart Diseases in Zabrze, School of Medicine with the Division \\ of Dentistry in Zabrze, Medical University of Silesia in Katowice, Zabrze, Poland \\ 9 Department of Invasive Cardiology, Centre of Postgraduate Medical Education, Warsaw, Poland \\ 10 Department of Interventional Cardiology and Angiology, The Cardinal Stefan Wyszyński National Institute of Cardiology, Warsaw, Poland \\ 11 Department of Cardiology and Structural Heart Diseases, Medical University of Silesia, Katowice, Poland \\ 12 Department of Interventional Cardiology, Institute of Cardiology, Jagiellonian University Medical College, Kraków, Poland \\ 13 Institute of Cardiology, Jagiellonian University Medical College, Kraków, Poland
}

\section{EDITORIALS}

by Agostoni et al, see p. 508

and Di Gioia et al, see p. 510

Correspondence to: Rafał Januszek, MD, PhD, Department of Cardiology and Cardiovascular Interventions, University Hospital, ul. Jakubowskiego 2, 30-688 Kraków, Poland, phone: +48124002250, email: jaanraf@interia.pl Received: January 28, 2020. Revision accepted: April 5, 2020 Published online: April 8, 2020. Kardiol Pol. 2020; 78 (6): 529-536 doi:10.33963/KP.15286 Copyright by the Author(s), 2020

\section{ABSTRACT}

BACKGROUND The association between periprocedural complications and the type of vascular access in patients treated with percutaneous coronary intervention (PCI) and rotational atherectomy (RA) has not been investigated as frequently as in an overall group of patients treated with PCI.

AIMS The aim of this study was to assess the associations between the type of vascular access and selected periprocedural complications in a group of patients treated with PCI and RA.

METHODS Based on a nationwide Polish registry (National Registry of Percutaneous Coronary Interventions [ORPKI]), we analyzed 536826 patients treated with PCI between the years 2014 and 2018. The study included 2713 patients $(0.5 \%$ of the overall group of patients treated with PCI $[n=536826])$ treated with PCI and RA. Among them, 1018 (37.5\%) were treated via femoral access, and 1653 (60.9\%) via radial access. Subsequently, these patients were subject to comparison, which was proceeded by propensity score matching.

RESULTS Following propensity score matching, multiple regression analysis revealed that patients undergoing PCI via femoral access experienced coronary artery perforation significantly less frequently than those managed via radial access (odds ratio, $0.29 ; 95 \% \mathrm{CI}, 0.08-0.92 ; P=0.04$ ). We did not observe any significant associations between the type of vascular access and the periprocedural mortality rate $(P=0.99)$, cardiac arrest $(P=0.41)$, puncture-site bleeding $(P=0.99)$, allergic reaction $(P=0.32)$, myocardial infarction $(P=0.48)$, no-reflow phenomenon $(P=0.82)$, or the overall complication rate $(P=0.31)$.

CONCLUSIONS In patients treated with PCI and RA, femoral access is associated with a lower rate of coronary artery perforations as compared with radial access. 


\section{WHAT'S NEW?}

The association between procedure-related complications and the type of vascular access in patients treated with percutaneous coronary interventions (PCIs) and rotational atherectomy $(\mathrm{RA})$ has not been investigated as frequently as in an overall group of patients treated with PCI. Of note, studies of large patient groups are scarce. The type of vascular access may be associated with particular, sometimes even life-threatening, procedure-related complications. Therefore, based on a nationwide Polish registry (National Registry of Percutaneous Coronary Interventions [ORPKI]), we analyzed 536826 patients treated with PCI. We found 2713 patients treated with PCI and rotational atherectomy. After propensity score matching and multiple regression analysis, the main finding of this study was that femoral access was significantly less often related to coronary artery perforation compared with the radial approach. However, the frequency of coronary artery perforations remains low regardless of the type of vascular access, with the femoral approach being preferred in selected cases.

\section{KEY WORDS}

percutaneous coronary intervention, periprocedural complications, rotational atherectomy, vascular access

INTRODUCTION The association between periprocedural complications and long-term clinical outcomes depending on the femoral or radial artery approach in the overall group of patients treated with percutaneous coronary interventions (PCIs) without rotational atherectomy (RA) has been widely investigated and the results of these studies were published. ${ }^{1}$ Nowadays, the radial approach is preferred over femoral due to several advantages. Among others, it is associated with fewer local complications, mainly including bleeding at the puncture site, and consequently with the possibility of faster discharge from the hospital. ${ }^{1}$ However, patients treated with PCI and RA comprise a specific population, which modifies the well-recognized spectrum of complications related to the type of vascular access applied in those receiving percutaneous treatment. ${ }^{2}$ Previous studies demonstrated that selected periprocedural complications are linked to RA. ${ }^{2}$ The RA procedure was found to be an independent predictor of coronary artery perforation (CAP) in the overall group of patients treated with $\mathrm{PCI} .{ }^{2}$ In the era of a decreasing aversion to radial access and its greater popularity compared with the femoral approach, even in patients at high periprocedural risk associated with undergoing complex percutaneous revascularization procedures, we decided to examine the differences in periprocedural complications regarding the vascular access site in this selected group of patients. ${ }^{3}$

The aim of the current study was to investigate the association between procedure-related complications and the type of arterial approach (femoral versus radial) in patients treated with PCI and RA.

METHODS Study design and patients This retrospective analysis was performed using prospectively collected data. ${ }^{2}$ These were obtained from the National Registry of Percutaneous Coronary Interventions (ORPKI), which is maintained in cooperation with the Association of Cardiovascular Interventions of the Polish Cardiac Society. The registry has been already described elsewhere. ${ }^{2,3}$ The study covered data obtained from the registry between January 2014 and December 2018. We selected 2713 patients treated with PCI and RA out of 536826 undergoing PCI in the analyzed time interval. The technical aspects of the procedure, such as the choice of the access site, sheath size, and catheter size, were at the operator's discretion. Furthermore, periprocedural anticoagulation and indications for PCI as well as the stent type remained at the first operator's discretion. The protocol complied with the 1964 Declaration of Helsinki and all study participants provided written informed consent to undergo a percutaneous intervention. Due to the retrospective nature of the collected data and the registry, no ethics committee approval was required.

Endpoints Primary study endpoints included periprocedural complications such as death, cardiac arrest, puncture-site bleeding, allergic reaction, coronary artery perforation, myocardial infarction, no-reflow phenomenon, and the overall complication rate. The definitions of particular complications were adopted in accordance with the applicable guidelines of the European Society of Cardiology, but the diagnosis of each complication was ultimately at the operator's discretion. ${ }^{4}$ The overall complication rate was defined as the number of patients with at least 1 of the periprocedural complications assessed.

Statistical analysis Continuous variables were expressed as mean (SD) or median with the first and third quartiles, as appropriate. Nominal variables were presented as number and percentage. The study groups were compared using the $t$ test for continuous variables or the $\mathrm{X}^{2}$ test for nominal variables of their nonparametric equivalents, as appropriate. Standardized differences were calculated for all baseline variables before and after matching. Out of all baseline demographic characteristics, those with a $P$ value less than 0.2 or standardized differences higher than $10 \%$ for differences across the groups were included in the logistic regression model used for propensity score matching. This was performed using the nearest-neighbor algorithm. The groups were considered balanced if standardized differences for each of the analyzed baseline demographic characteristics were lower than $10 \%$. The effects of femoral access on death, cardiac arrest, coronary artery perforation, puncture-site bleeding, and no-reflow phenomenon were assessed using mixed-effect models to account for matching. Models were constructed with procedural data as covariates, aimed at adjustment. Statistical analysis was performed using the $\mathrm{R}$ software, version 3.5.3 


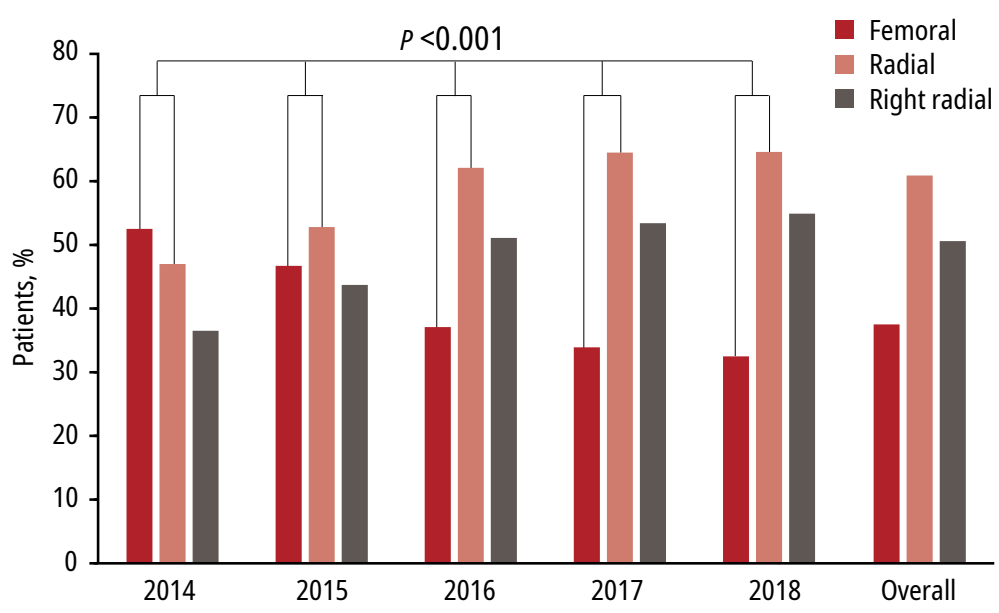

FIGURE 1 Particular types of vascular access (femoral, radial, and right radial) in patients undergoing percutaneous coronary intervention with rotational atherectomy in the years 2014 to 2018
(R Foundation for Statistical Computing, Vienna, Austria), with the following packages: MatchIt, version 3.0.2 and lme4, version 1.1-21.

RESULTS Study population The study included 2713 patients treated with PCI and RA who were registered in the ORPKI database within the years 2014 to 2018. Among them, 1018 (37.5\%) were treated via femoral access, and 1653 (60.9\%) via radial access. In 42 patients (1.54\%), other approaches were used for PCI. Data regarding vascular access sites in the whole study group by the following years are shown in FIGURE 1 .

Patient characteristics At baseline and before propensity score matching, the group of patients treated using the femoral approach was characterized by a greater burden of concomitant diseases and history of cardiovascular interventions.

TABLE 1 Patient characteristics

\begin{tabular}{|c|c|c|c|c|c|}
\hline \multicolumn{2}{|l|}{ Clinical variable } & $\begin{array}{l}\text { Overall } \\
(n=2671)\end{array}$ & $\begin{array}{l}\text { Radial } \\
\text { (n [\%], } 1653 \text { [61.9]) }\end{array}$ & $\begin{array}{l}\text { Femoral } \\
\text { (n [\%], } 1018 \text { [38.1]) }\end{array}$ & $P$ value \\
\hline \multicolumn{2}{|c|}{ Age, y, mean (SD); median (IQR) } & $\begin{array}{l}71.9(9.59) \\
72(65-79)\end{array}$ & $\begin{array}{l}71.85 \text { (9.56); } \\
71(65-79)\end{array}$ & $\begin{array}{l}71.99(9.64) ; \\
72(65-79.25)\end{array}$ & 0.7 \\
\hline \multicolumn{2}{|l|}{ Male sex } & $1801(67.5)$ & $1129(68.5)$ & $672(66)$ & 0.2 \\
\hline \multicolumn{2}{|l|}{ Hypertension } & $2005(75.1)$ & $1245(75.3)$ & $760(74.7)$ & 0.71 \\
\hline \multicolumn{2}{|l|}{ Diabetes } & $874(32.7)$ & $547(33.1)$ & $327(32.1)$ & 0.61 \\
\hline \multicolumn{2}{|l|}{ Prior cerebral stroke } & $116(4.3)$ & $78(4.7)$ & $38(3.7)$ & 0.24 \\
\hline \multicolumn{2}{|l|}{ Prior MI } & $1318(49.3)$ & $797(48.2)$ & $521(51.2)$ & 0.14 \\
\hline \multicolumn{2}{|l|}{ Prior PCI } & $1452(54.4)$ & $887(53.7)$ & $565(55.5)$ & 0.35 \\
\hline \multicolumn{2}{|l|}{ Prior CABG } & $358(13.4)$ & $202(12.2)$ & $156(15.3)$ & 0.02 \\
\hline \multicolumn{2}{|l|}{ Smoking } & $420(15.7)$ & $267(16.1)$ & $153(15)$ & 0.44 \\
\hline \multicolumn{2}{|l|}{ Psoriasis } & $7(0.26)$ & $6(0.36)$ & $1(0.1)$ & 0.26 \\
\hline \multicolumn{2}{|l|}{ Kidney disease } & $306(11.5)$ & $161(9.7)$ & $145(14.2)$ & $<0.001$ \\
\hline \multicolumn{2}{|l|}{ COPD } & $76(3)$ & $51(3.2)$ & $25(2.7)$ & 0.47 \\
\hline \multirow[t]{5}{*}{ Clinical presentation } & $\begin{array}{l}\text { Stable } \\
\text { angina }\end{array}$ & $1540(57.9)$ & $1023(62.2)$ & $517(51.1)$ & \multirow[t]{5}{*}{$<0.001$} \\
\hline & $\begin{array}{l}\text { Unstable } \\
\text { angina }\end{array}$ & $606(22.8)$ & $327(19.9)$ & $279(27.6)$ & \\
\hline & NSTEMI & $301(11.3)$ & $171(10.4)$ & $130(12.8)$ & \\
\hline & STEMI & $198(7.45)$ & $115(7)$ & $83(8.2)$ & \\
\hline & Other & $12(0.45)$ & $9(0.55)$ & $3(0.3)$ & \\
\hline \multirow[t]{4}{*}{ Killip class } & I & $732(93.5)$ & $463(92.2)$ & $269(95.8)$ & \multirow[t]{4}{*}{$<0.001$} \\
\hline & II & $38(4.9)$ & $32(6.4)$ & $6(2.1)$ & \\
\hline & III & $8(1)$ & $7(1.4)$ & $1(0.3)$ & \\
\hline & IV & $5(0.6)$ & 0 & $5(1.8)$ & \\
\hline
\end{tabular}

Data are presented as number (percentage) of patients unless otherwise indicated.

Abbreviations: CABG, coronary artery bypass grafting; COPD, chronic obstructive pulmonary disease; MI, myocardial infarction; NSTEMI, non-ST-segment elevation myocardial infarction; PCI, percutaneous coronary intervention; STEMI, ST-segment elevation myocardial infarction 
The difference reached statistical significance for prior coronary artery bypass grafting $(P=0.02)$ and kidney failure $(P<0.001)$. The percentage of patients with unstable angina and myocardial infarction was also significantly higher in those treated via femoral access $(P<0.001)$ (table 1).

Procedural indices Considering the results of coronary angiography, patients treated via femoral access presented left main coronary artery involvement more frequently than those treated with the radial approach. However, these differences were nonsignificant $(P=0.07)$. Nevertheless, they were significant regarding the percentage of patients in whom PCI was performed within the left main coronary artery. This occurred more often in those treated using the femoral approach $(P<0.001)$. Also, patients treated via femoral access were characterized by a significantly greater percentage of those treated with PCI within chronically occluded coronary arteries, which was reflected in the comparison of Thrombolysis in Myocardial Infarction (TIMI) grades $(P<0.001)$ and PCI within chronic total occlusions $(P<0.001)$. Furthermore, the mean amount of contrast agent was greater in patients treated using the femoral approach $(P<0.001)$ (tABle 2$)$.

Periprocedural complications Before propensity score matching, particular complications were compared and no statistical significance was found for any comparison (TABLE3). Although the rate of overall periprocedural complications was greater in patients treated via radial access compared with those in whom femoral access was used, it did not show statistical significance ( $2.9 \%$ vs $2.46 \%$; $P=0.54$ ). The difference was mainly related to the higher rate of cardiac arrests $(0.73 \%$ vs $0.59 \% ; P=0.8)$, CAPs (1.09\% vs $0.49 \% ; P=0.13)$, and cerebral strokes (0.28\% vs $0 \% ; P=0.55)$ in patients treated via radial access as compared with those managed using the femoral approach.

Propensity score matching After propensity score matching, the overall number of patients decreased to 855 in each group. The comparison of patients treated via femoral or radial access, after propensity score matching, is presented in TABLE 4.

Predictors of periprocedural complications: vascular access Multivariate analysis revealed that the type of vascular access was not significantly associated with periprocedural mortality $(P=0.99)$, allergic reaction $(P=0.32)$, or puncture-site bleeding $(P=0.99)$ rates. No significant differences were also found for periprocedural myocardial infarction (odds ratio [OR], 0.55; 95\% CI, 0.09-2.78; $P=0.48)$, no-reflow phenomenon (OR, 1.2; 95\% CI, 0.23-0.59; $P=0.82$ ), cardiac arrest (OR, 0.62; 95\% CI, 0.18-1.92;
$P=0.41$ ), or the overall complication rate (OR, 0.73 ; 95\% CI, 0.39-1.34; $P=0.31$ ). Compared with the radial approach, the femoral approach was found to be one of the factors associated with the lower rate of CAPs (OR, 0.29; 95\% CI, 0.08$0.92 ; P=0.04$ ) (FIGURE 2).

DISCUSSION The main finding of this study was that patients undergoing percutaneous coronary revascularization with subsequent mechanical plaque modification with RA and in whom the radial approach was used are at greater risk of coronary artery perforation as compared with those managed via femoral access.

Patients treated with RA belong to a specific cohort of patients, usually with a high burden of concomitant disease. This particularly occurs in the case of calcium deposition in the arterial wall, which could be found more often in patients with kidney failure, diabetes, previous coronary revascularizations, or at older age. ${ }^{5,6}$ This also applies to patients with multivessel diseases who are disqualified from cardiac surgery with bypass implantation. ${ }^{7}$ In this population, mechanical lesion preparation plays a pivotal role and facilitates or, in a considerable percentage of cases, even enables percutaneous revascularization. ${ }^{8}$ The current European guidelines on RA in clinical practice suggest using any vascular access. They mainly focus on the possibility of performing the procedure considering the diameter of the guiding catheter that can be achieved depending on the type of access. ${ }^{9}$ This consensus pays less attention to the quality of the procedure or the risk of complications associated with RA itself, which can be life-threatening in certain situations. It indicates that the main predictors of coronary artery perforation include the burr size, the ratio of burr to vessel sizes, artery tortuosity or the length of the calcified lesion, and other indices of the culprit lesion and the artery. ${ }^{9}$ We could not include these parameters characterizing the culprit lesion and the target vessel as well as the burr size, because the analyzed database did not contain such data. In our analysis, we concentrated on the available data and comparison of vascular access types. However, expert opinions published in cooperation with the Association of Cardiovascular Interventions of the Polish Cardiac Society draw attention to the link between the burr diameter and planned vascular access type. ${ }^{10}$ The authors suggested that radial access can be successfully used for smaller burr diameters, whereas for larger burr diameters, rarely implemented, a $7 \mathrm{Fr}$ guiding catheter is needed. Despite using thin-walled sheaths, sheathless guiding catheters, or other maneuvers, it may be difficult to achieve radial access with such a diameter in many cases. Thin-walled sheaths enable clinicians to apply 7 Fr guiding catheters to use radial access. In 
TABLE 2 Procedural characteristics

\begin{tabular}{|c|c|c|c|c|c|}
\hline \multicolumn{2}{|l|}{ Procedural index } & $\begin{array}{l}\text { Overall } \\
(n=2671)\end{array}$ & $\begin{array}{l}\text { Radial access } \\
(n=1653[61.9 \%])\end{array}$ & $\begin{array}{l}\text { Femoral access } \\
(n=1018[38.1 \%])\end{array}$ & $P$ value \\
\hline \multirow{3}{*}{$\begin{array}{l}\text { Type of the culprit } \\
\text { lesion }\end{array}$} & De novo & $3716(98.2)$ & $2285(98.3)$ & $1431(98)$ & 0.48 \\
\hline & Restenosis & $58(1.5)$ & $32(1.4)$ & $26(1.8)$ & 0.32 \\
\hline & Thrombosis & $10(0.03)$ & $7(0.3)$ & $3(0.2)$ & 0.57 \\
\hline \multirow{6}{*}{$\begin{array}{l}\text { Site of the culprit } \\
\text { lesion }\end{array}$} & Right coronary artery & $1261(33.3)$ & $763(32.8)$ & $498(34.1)$ & 0.41 \\
\hline & LMCA & $301(8)$ & $155(6.7)$ & $146(10)$ & $<0.001$ \\
\hline & LAD & $1592(42.1)$ & $1030(44.3)$ & $562(38.5)$ & $<0.001$ \\
\hline & Circumflex artery & $596(15.75)$ & $353(15.2)$ & $243(16.63)$ & 0.23 \\
\hline & Intermediate artery & $32(0.8)$ & $22(0.95)$ & $10(0.7)$ & 0.39 \\
\hline & Saphenous vein graft & $2(0.05)$ & $1(0.05)$ & $1(0.07)$ & 0.74 \\
\hline \multirow{5}{*}{$\begin{array}{l}\text { Coronary } \\
\text { angiography }\end{array}$} & SVD & $725(50.6)$ & $472(51.6)$ & $253(48.9)$ & \multirow[t]{5}{*}{0.7} \\
\hline & MVD and no LMCA & $494(34.4)$ & $325(35.5)$ & $169(32.6)$ & \\
\hline & MVD and LMCA & $175(12.2)$ & $99(10.8)$ & $76(14.7)$ & \\
\hline & Separate LMCA & $21(1.5)$ & $10(1.1)$ & $11(2.1)$ & \\
\hline & Other & $19(1.3)$ & $10(1.1)$ & $9(1.7)$ & \\
\hline \multirow{4}{*}{$\begin{array}{l}\text { TIMI grade } \\
\text { before PCI }\end{array}$} & 0 & $354(13.6)$ & $184(11.6)$ & $170(16.9)$ & \multirow[t]{4}{*}{$<0.001$} \\
\hline & 1 & $409(15.8)$ & $257(16.2)$ & $152(15.1)$ & \\
\hline & 2 & $512(19.7)$ & $346(21.8)$ & $166(16.5)$ & \\
\hline & 3 & $1318(50.8)$ & $801(50.4)$ & $517(51.4)$ & \\
\hline \multirow{4}{*}{$\begin{array}{l}\text { TIMI grade after } \\
\text { PCI }\end{array}$} & 0 & $17(0.65)$ & $9(0.56)$ & $8(0.8)$ & \multirow[t]{4}{*}{0.45} \\
\hline & 1 & $16(0.61)$ & $11(0.68)$ & $5(0.5)$ & \\
\hline & 2 & $60(2.3)$ & $32(2)$ & $28(2.8)$ & \\
\hline & 3 & $2515(96.4)$ & $1554(96.7)$ & $961(95.9)$ & \\
\hline \multicolumn{2}{|l|}{ Thrombectomy } & $19(0.71)$ & $16(0.97)$ & $3(0.29)$ & 0.05 \\
\hline \multicolumn{2}{|c|}{ Chronic total occlusion } & $31(5.82)$ & $10(3)$ & $21(10.55)$ & $<0.001$ \\
\hline \multicolumn{2}{|l|}{ Bifurcation } & $58(10.9)$ & $38(11.4)$ & $20(10.05)$ & 0.62 \\
\hline \multicolumn{2}{|c|}{ Fractional flow reserve } & $13(0.85)$ & $11(1.14)$ & $2(0.35)$ & 0.14 \\
\hline \multicolumn{2}{|c|}{ Intravascular ultrasound } & $85(5.56)$ & $45(4.7)$ & $40(7.05)$ & 0.06 \\
\hline \multicolumn{2}{|l|}{ ОСТ } & $4(0.26)$ & $2(0.21)$ & $2(0.35)$ & 0.63 \\
\hline \multirow[t]{4}{*}{ Type of PCI } & Drug-eluting stent & 3521 (93.1) & $2172(93.5)$ & $1349(92.4)$ & 0.21 \\
\hline & Bare-metal stent & $17(0.4)$ & $11(0.5)$ & $6(0.4)$ & 0.78 \\
\hline & $\begin{array}{l}\text { Bioresorbable } \\
\text { scaffold }\end{array}$ & $53(1.4)$ & $19(0.8)$ & $34(2.3)$ & $<0.001$ \\
\hline & Other & $193(5.1)$ & $122(5.2)$ & $71(4.9)$ & 0.59 \\
\hline \multicolumn{2}{|c|}{$\begin{array}{l}\text { Radiation dose, Gy, mean (SD); median } \\
\text { (IQR) }\end{array}$} & $\begin{array}{l}1.59(1.26) \\
1.23(0.71-2.07)\end{array}$ & $\begin{array}{l}1.56(1.26) ; \\
1.21(0.7-2.03)\end{array}$ & $\begin{array}{l}1.64(1.33) \\
1.3(0.75-2.13)\end{array}$ & 0.13 \\
\hline \multicolumn{2}{|c|}{$\begin{array}{l}\text { Contrast dose, ml, mean (SD); median } \\
\text { (IQR) }\end{array}$} & $\begin{array}{l}210(91.3) ; \\
200(150-250)\end{array}$ & $\begin{array}{l}201.9(80.7) ; \\
200(150-250)\end{array}$ & $\begin{array}{l}223.5(105.2) \\
200(150-270)\end{array}$ & $<0.001$ \\
\hline
\end{tabular}

Data are presented as number (percentage) unless otherwise indicated.

Abbreviations: IQR, interquartile range; LAD, left anterior descending artery; LMCA, left main coronary artery; MVD, multivessel disease; OCT, optical coherence tomography; SVD, single-vessel disease; TIMI, Thrombolysis in Myocardial Infarction; others, see TABLE 1 
TABLE 3 Procedure-related complications

\begin{tabular}{lllll}
$\begin{array}{l}\text { Type of periprocedural } \\
\text { complication }\end{array}$ & $\begin{array}{l}\text { Overall } \\
(\mathrm{n}=2671)\end{array}$ & $\begin{array}{l}\text { Radial access } \\
(\mathrm{n}[\%], 1653[61.9])\end{array}$ & $\begin{array}{l}\text { Femoral access } \\
(\mathrm{n}[\%], 1018[38.1])\end{array}$ & $P$ value \\
\hline Any & $73(2.73)$ & $48(2.9)$ & $25(2.46)$ & 0.54 \\
\hline Death & $5(0.19)$ & $4(0.24)$ & $1(0.1)$ & 0.65 \\
\hline MI & $10(0.37)$ & $6(0.36)$ & $4(0.39)$ & $<0.99$ \\
\hline No-reflow phenomenon & $12(0.45)$ & $7(0.42)$ & $5(0.49)$ & 0.77 \\
\hline Puncture-site bleeding & $6(0.22)$ & $2(0.12)$ & $4(0.39)$ & 0.2 \\
\hline Cardiac arrest & $18(0.67)$ & $12(0.73)$ & $6(0.59)$ & 0.8 \\
\hline Allergic reaction & $3(0.11)$ & $2(0.12)$ & $1(0.1)$ & $<0.99$ \\
\hline CAP & $23(0.86)$ & $18(1.09)$ & $5(0.49)$ & 0.13 \\
\hline Cerebral stroke & $3(0.27)$ & $3(0.42)$ & 0 & 0.55 \\
\hline Dissection & $3(0.27)$ & $2(0.28)$ & $1(0.27)$ & $<0.99$ \\
\hline
\end{tabular}

Data are presented as number (percentage).

Abbreviations: CAP, coronary artery perforation; others, see TABLE 1

TABLE 4 Patient characteristics after propensity score matching analysis

\begin{tabular}{|c|c|c|c|c|}
\hline \multicolumn{2}{|l|}{ Clinical variable } & Radial access $(n=855)$ & Femoral access $(n=855)$ & $P$ value \\
\hline \multicolumn{2}{|l|}{ Age, y, mean (SD) } & $71.57(9.56)$ & $91.98(9.73)$ & 0.38 \\
\hline \multicolumn{2}{|l|}{ Male sex } & $567(67.1)$ & $559(66.2)$ & 0.71 \\
\hline \multicolumn{2}{|l|}{ Weight, kg, mean (SD) } & 79.64 (15.71) & $78.81(14.87)$ & 0.26 \\
\hline \multicolumn{2}{|l|}{ Hypertension } & $628(74.3)$ & $620(14.9)$ & 0.69 \\
\hline \multicolumn{2}{|l|}{ Diabetes } & $272(32.2)$ & $269(31.8)$ & 0.91 \\
\hline \multicolumn{2}{|l|}{ Prior cerebral stroke } & $40(4.7)$ & $33(3.9)$ & 0.47 \\
\hline \multicolumn{2}{|l|}{ Prior MI } & $436(51.6)$ & $439(52)$ & 0.92 \\
\hline \multicolumn{2}{|l|}{ Prior PCI } & $486(57.5)$ & $485(57.4)$ & 1 \\
\hline \multicolumn{2}{|l|}{ Prior CABG } & $124(14.7)$ & $129(15.3)$ & 0.78 \\
\hline \multicolumn{2}{|l|}{ Smoking } & $144(17)$ & $133(15.7)$ & 0.51 \\
\hline \multicolumn{2}{|l|}{ Kidney disease } & $115(13.6)$ & $126(14.9)$ & 0.48 \\
\hline \multirow[t]{5}{*}{ Clinical presentation } & Stable angina & $484(57.3)$ & $470(55.6)$ & \multirow[t]{5}{*}{0.8} \\
\hline & Unstable angina & $235(27.8)$ & $245(29)$ & \\
\hline & NSTEMI & $99(11.7)$ & $99(11.7)$ & \\
\hline & STEMI & $22(2.6)$ & $28(3.3)$ & \\
\hline & Other & $5(0.6)$ & $3(0.4)$ & \\
\hline \multirow[t]{4}{*}{ TIMI grade before PCI } & 0 & $107(12.7)$ & $151(17.9)$ & \multirow[t]{4}{*}{0.001} \\
\hline & 1 & $120(14.2)$ & $122(14.4)$ & \\
\hline & 2 & $183(21.7)$ & $132(15.6)$ & \\
\hline & 3 & $435(51.5)$ & $440(52.1)$ & \\
\hline \multirow[t]{4}{*}{ TIMI grade after PCI } & 0 & $4(0.5)$ & $7(0.8)$ & \multirow[t]{4}{*}{0.55} \\
\hline & 1 & $5(0.6)$ & $5(0.6)$ & \\
\hline & 2 & $17(2)$ & $24(2.8)$ & \\
\hline & 3 & 819 (96.9) & 809 (95.7) & \\
\hline
\end{tabular}

Data are presented as number (percentage) unless otherwise indicated.

Abbreviations: see TABLES 1 and 2 
Myocardial infarction

No-reflow phenomenon

Cardiac arrest

Coronary artery perforation

Overall complication rate

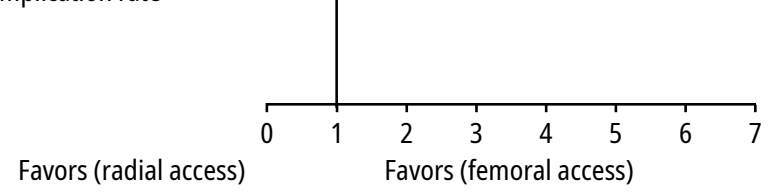

FIGURE 2 The association between the type of vascular access (femoral versus radial) and the likelihood of a particular complication in patients treated with percutaneous coronary intervention and rotational atherectomy. Dots represent estimates ( $95 \%$ CIs), and lines, selected periprocedural complications. turn, hydrophilic guiding catheters allow them to enter through the radial artery in certain situations, eg, in interventions carried out in narrow or constricted arteries. Expert opinions also emphasize the importance of coaxial guiding catheter positioning during PCI with RA. ${ }^{10}$ When catheter maneuvering is challenging, which often occurs in the case of radial access, or when less stable catheters such as sheathless guiding catheters are used, coaxial positioning may be very difficult or even impossible in some patients. This can be a potential cause of a number of serious complications, such as the release of embolic material into the aorta, looping and cutting the guidewire, or instability of the burr and subsequent possible CAP or even burr entrapment. One way to reduce the risk of releasing the embolic material into the aorta or the occurrence of possible complications associated with target artery rotablation is to use burrs and guiding catheters of smaller diameters, which is aimed at plaque modification rather than its debulking. This method has recently gained a growing number of advocates. However, if burrs of smaller diameters are used, it may be problematic to sufficiently prepare the lesion for stent implantation. Inflations with cutting or high-pressure balloons can cause dissection, which is a contraindication to RA, or modification of the atherosclerotic plaque inside the artery in a way that prevents stent delivery. This may occur despite applying a variety of techniques, including the use of the so-called mother-and-child catheters. Then, it may be necessary to repass RA, also with a burr of a larger diameter. Coronary artery perforation is another complication of insufficient lesion preparation by RA (due to too small burr diameters), which is a consequence of too aggressive attempts to prepare the lesion for implantation of the stent with various balloon catheters. All these factors indicate that one of the key elements that should be considered in order to successfully perform the RA procedure is to choose the right diameter of the guiding catheter, which would permit its stable coaxial positioning during RA. This could be often provided only with the use of femoral access. However, after considering a number of threats related to this approach, radial access remains the first-choice option. ${ }^{10}$

In previous studies, the particular type of vascular access was not confirmed to be a predictor of CAPs in an overall group of patients treated with PCIs. ${ }^{2,3}$ One of the recently published studies showed that RA was highly effective and had a relatively low percentage of complications. However, it was associated with selected complications, which occurred more frequently than when the entire group of patients undergoing PCI without RA was analyzed. ${ }^{11}$ Considering procedure-related complications, CAP was found to be the most typical one, excluding rotablation complications such as burr entrapment or breaking the burr. In one of the largest recent studies, it was reported that the frequency of CAP in an overall group of patients treated with RA was $0.2 \%$, that is, lower than in the presented analysis, whereas the dissection rate was comparable and estimated at $0.3 \% .^{12}$ The mortality rate of $0.2 \%$ reported in that study was also similar to our findings. ${ }^{12}$

Studies on procedure-related complications in patients treated with PCI and RA, which have been published so far, usually reported data on the entire course of hospitalization. That is why they demonstrated a higher frequency of these complications compared with the rates obtained in our analysis. ${ }^{13,14}$ Of note, the data published in this work relate only to complications occurring in the catheterization laboratory, and not throughout the entire hospitalization. In addition, there is an issue of underestimating complications and not reporting them. However, in the latter case, this should not affect the general trends due to the large number of patients observed. Nevertheless, a recent study showed that radial access did not cause inferior outcomes in long-term follow-up and was associated with shorter hospitalization time and lower frequency of complications related to the puncture site..$^{13}$ Apart from that, the authors reported that the frequency of main adverse cardiac events during hospitalization was almost 2-fold higher in the group of patients treated via femoral access as compared with radial access $(17.1 \%$ vs $8.9 \% ; P=0.33)$. This difference was mainly influenced by the higher frequency of target lesion revascularizations. However, CAP rates were lower in the group of 
patients treated via radial access $(4.4 \%$ vs $7.3 \%$; $P=0.57)$. That study was conducted on a small group of patients and used a retrospective design. ${ }^{13}$ However, it showed that there are no consistent results and that they differ regarding the incidence of CAPs and other periprocedural complications.

In the analyzed group, 3 periprocedural cerebral strokes were found in the group of patients treated via radial access, while none were noted in those in whom femoral access was used. It can therefore be concluded that severely calcified atherosclerotic lesions in the aorta and the main arteries branching from the aortic arch, unsatisfactory intubation of the artery undergoing RA, and burr instability may contribute to an increased number of adverse cerebrovascular events related to PCI. In another recent study, no differences in treatment outcomes were found between patients with advanced aortic calcifications and those without, and the factors primarily determining follow-up prognosis included the presence of valvular disease or comorbidities. ${ }^{15}$

Strengths and limitations Undoubtedly, the large sample size is the greatest strength of the presented study, because analyses carried out in such a large group of patients undergoing RA are rare. However, among numerous limitations of this study, the design of analysis should be addressed first. Our research was retrospective, carried out based on a registry containing prospectively collected data. The disadvantages of such registry type include, but are not limited to, estimating the frequency of periprocedural complications only during the procedure and during the early postprocedural period when the patient is still in the catheterization laboratory. Another important issue is the fact that recognizing periprocedural complications was at the operator's discretion and depended on his or her knowledge, habits, or inclinations, which, unfortunately, imposes a bias. We could not analyze other well-recognized predictors of CAP in patients treated with rotablation, such as lesion and target vessel parameters characterizing the culprit lesion (length, diameter, site, tortuosity, bifurcations, trifurcation, etc), as well as the burr size or type of the rotablator guidewire, because the database did not contain such data. We also had no access to data regarding previous attempts of PCIs in the study patients and the use of other typical devices, such as scoring, cutting, or high-pressure balloons. These missing facts could significantly modify results and cause some bias.

Conclusions Femoral access, as opposed to radial, is related to lower rates of CAPs in patients treated with PCI and RA. Nevertheless, the percentage of patients treated with RA in whom CAP was observed is low, and percutaneous treatment seems to be far safer than surgical revascularization. Similarly, significantly less adverse events appear to be associated with puncture-site complications in the case of radial access, as compared with femoral, if advanced atherosclerosis and significant calcification of the arterial walls are present. Of note, the frequency of hemorrhagic complications related to the puncture site is more than 3 -fold higher for femoral access as compared with the radial approach.

\section{ARTICLE INFORMATION}

\section{CONFLICT OF INTEREST None declared.}

OPEN ACCESS This is an Open Access article distributed under the terms of the Creative Commons Attribution-Non Commercial-No Derivatives 4.0 International License (CC BY-NC-ND 4.0), allowing third parties to download articles and share them with others, provided the original work is properly cited, not changed in any way, distributed under the same license, and used for noncommercial purposes only. For commercial use, please contact the journal office at kardiologiapolska@ptkardio.pl.

HOW TO CITE Januszek R, Siudak Z, Malinowski KP, et al. Radial versus femoral access in patients treated with percutaneous coronary intervention and rotational atherectomy. Kardiol Pol. 2020; 78: 529-536. doi:10.33963/KP.15286

\section{REFERENCES}

1 Jolly SS, Yusuf S, Cairns J, et al; RIVAL Trial Group. Radial versus femoral access for coronary angiography and intervention in patients with acute coronary syndromes (RIVAL): a randomised, parallel group, multicentre trial. Lancet. 2011; 377: 1409-1420.

2 Januszek R, Siudak Z, Dziewierz A, et al. Predictors of in-hospital effectiveness and complications of rotational atherectomy (from the ORPKI Polish National Registry 2014-2016). Catheter Cardiovasc Interv. 2018; 92: 278-287.

3 Januszek R, Siudak Z, Reczuch K, et al. Current trends and procedural outcomes in the era of rotational atherectomy expansion in Poland in the period 2014-2017 (based on the nationwide ORPKI registry). Adv Interv Cardiol. 2019; 15: 158-166.

4 Thygesen $\mathrm{K}$, Alpert JS, Jaffe AS, et al. Fourth universal definition of myocardial infarction (2018). Eur Heart J. 2019; 40: 237-269.

5 Aoki J, Ikari Y, Sugimoto T, et al. Clinical outcome of percutaneous transluminal coronary rotational atherectomy in patients with end-stage renal disease. Circ J. 2003; 67: 617-621.

6 Januszek RA, Dziewierz A, Siudak Z, et al. Diabetes and periprocedural outcomes in patients treated with rotablation during percutaneous coronary interventions. Cardiol J. 2018 Sep 20. [Epub ahead of print].

7 Kübler $\mathrm{P}$, Zimoch W, Kosowski $\mathrm{M}$, et al. The use of rotational atherectomy in high-risk patients: results from a high-volume centre. Kardiol Pol. 2018; 76: 1360-1368.

8 Rheude T, Toelg R, Byrne RA, et al. Impact of target lesion location on procedural and angiographic outcomes of rotational atherectomy versus modified balloon angioplasty prior to drug-eluting stent implantation in severely calcified coronary lesions: a subgroup analysis of the PREPARE-CALC randomized trial. EuroIntervention. 2019 0ct 1. [Epub ahead of print].

9 Barbato E, Carrié D, Dardas P, et al; European Association of Percutaneous Cardiovascular Interventions. European expert consensus on rotational atherectomy. EuroIntervention. 2015; 11: 30-36.

10 Dobrzycki S, Reczuch K, Legutko J, et al. Rotational atherectomy in everyday clinical practice. Association of Cardiovascular Interventions of the Polish Society of Cardiology (Asocjacja Interwencji Sercowo-Naczyniowych Polskiego Towarzystwa Kardiologicznego - AISN PTK): expert opinion. Kardiol Pol. 2018; 76: 1576-1584. 11 Gorol J, Tajstra M, Hudzik B, et al. Comparison of outcomes in patients undergoing rotational atherectomy after unsuccessful coronary angioplasty versus elective rotational atherectomy. Adv Interv Cardiol. 2018; 14: 128-134.

12 Okamoto N, Ueda H, Bhatheja S, et al. Procedural and one-year outcomes of patients treated with orbital and rotational atherectomy with mechanistic insights from optical coherence tomography. EuroIntervention. 2019; 14: 1760-1767.

13 You W, Wu XQ, Ye F, Chen SL. Advantages of transradial rotational atherectomy versus transfemoral approach in elderly patients with hard-handling calcified coronary lesions - a single center experience. Acta Cardiol Sin. 2018; 34: 464-471.

14 Sakakura K, Taniguchi Y, Yamamoto K, et al. Comparison of complications with a $1.25-\mathrm{mm}$ versus a $1.5-\mathrm{mm}$ burr for severely calcified lesions that could not be crossed by an intravascular ultrasound catheter. Cardiovasc Interv Ther. 2019 Jul 20. [Epub ahead of print].

15 Kotronias RA, Scarsini R, Gibbs T, et al. Safety of rotational atherectomy using the radial access in patients with severe aortic stenosis. Am J Cardiol. 2019; 124: 381-388. 